Journal of Innovative Optical Health Sciences

Vol. 8, No. 4 (2015) 1502003 (1 page)

(c) The Author

DOI: $10.1142 /$ S1793545815020034

\title{
Foreword to the Special Issue Celebrating Prof. Valery Tuchin's 70th Birthday
}

Published 13 July 2015

We are very pleased and honored to have the opportunity to dedicate a series of papers to our dear friend, mentor and colleague, Valery V. Tuchin, to commemorate the occasion of his 70th birthday. Prof. Tuchin is one of the founders of the Biophotonics field whose remarkable work has advanced the frontiers of lightTissue interaction. He is best known for his textbooks such as Tissue Optics: Light Scattering Methods and Instruments for Medical Diagnosis and Handbook of Biophotonics, but his research encompasses virtually all aspects of optical measurements in biomedicine with incredible $400+$ peer-Reviewed publications.

Valery was born on February 4, 1944. He received his MS degree in Radiophysics and Electronics (1966), PhD degree in Optics (1973), and Doctor of Science (DSc) degree in Quantum Radiophysics (1982), all from Saratov State University (SSU), Saratov, Russia, where he continued his scientific career and still holds his primary appointment. He is currently a Professor and the Chair of the Optics and Biophotonics Department at the SSU. He heads the Laboratory of Laser Diagnostics of Technical and Living Systems of Precision Mechanics and Control Institute, Russian Academy of Sciences and Multidisciplinary Laboratory on Biophotonics of Tomsk State University. He is also a director of the Research-Educational Institute of Optics and Biophotonics at SSU.

Prof. Tuchin's contributions have been recognized by a great number of research and scholar awards. Just a few of them: He is a member of the Russian Academy of Natural Sciences and the International Academy of Informatization; he was awarded Honored Science Worker of the Russian Federation (1999), SPIE Fellow (2004), SPIE Educator Award (2007), and Chime Bell Prize of Hubei Province, China (2014).

Among Valery's greatest contributions is his mentorship of junior colleagues around the world. He has trained more than 200 graduate students; most of them currently take leadership positions in academia and industry around the globe. Working with Valery has shown us what dedication, honor, respect, hard work and professionalism mean and what they can accomplish. We extend our sincere best wishes for Valery's birthday and look forward to continuing our interactions in future.

This issue includes 11 papers from Valery's students, collaborators and friends. We thank all the authors for their contributions to this special issue.

Kirill V. Larin and Dan Zhu

This is an Open Access article published by World Scientific Publishing Company. It is distributed under the terms of the Creative Commons Attribution 3.0 (CC-BY) License. Further distribution of this work is permitted, provided the original work is properly cited. 